\title{
Static Voltage Stability of Reconfigurable Radial Distribution System Considering Voltage Dependent Load Models
}

\author{
Varaprasad Janamala $^{1 *}$, Thandava Krishna Sai Pandraju ${ }^{1,2}$ \\ ${ }^{1}$ Dept. of Electrical and Electronics Engineering, School of Engineering and Technology, CHRIST (Deemed to be University), \\ Bangalore 560074, Karnataka, India \\ ${ }^{2}$ Dept. of Electrical and Electronics Engineering, Dhanekula Institute of Engineering \& Technology, Vijayawada 521139, \\ Andhra Pradesh, India
}

Corresponding Author Email: varaprasad.janamala@christuniversity.in

https://doi.org/10.18280/mmep.070316

Received: 9 June 2020

Accepted: 23 August 2020

\section{Keywords:}

voltage stability analysis, radial distribution system, network reconfiguration, voltagedependent load modeling

\begin{abstract}
This paper presents the static voltage stability analysis of RDS. Initially the performance of RDS is evaluated using backward/forward load flow considering voltage-dependent load modeling. Later, the load flow solution is used for determining the static voltage stability of the system. The analysis is performed for different type of loads such as constant power, constant current, constant impedance, residential, industrial, commercial, agricultural and electric vehicle loads. The simulations are performed for standard and optimal reconfigured topology of standard IEEE 33-bus test system. The comparative study reveals the importance of load type and topology while assessing the static stability analysis of radial distribution systems.
\end{abstract}

\section{INTRODUCTION}

The continuously increasing demand for electricity and non-expanding transmission and distribution networks have been major reasons for operating the power systems closer to their security margins. On the other side, small investments due to the lack of profits and right-of-way problems have become some of the issues for investment and expansion in these sectors. Under this scenario, operating the power systems in safe zones has become a challenging task to the system operator. In the history, various power system blackouts around the world have highlighted the need of preventive and corrective measures [1]. Also, the assessment of voltage stability using a simple and accurate assessment technique for voltage stability margin (VSM) or critical loading margin (CLM) is inevitable. The major application of VSM is to trigger counter measures in system operational and planning stages. In simple words, VSM is the maximum allowable loading condition of any power system before it starts the scenario of voltage collapse. In specific, the voltage drop increases across the system elements under continuously increasing load demand and system said to be at insolvency state and apparently, the conventional load flow methods fail to converge. The loading level from base case to insolvency is considered as maximum loadability or VSM of the system. This margin is dependent on various system running conditions including its topology and different controllable and uncontrollable variables and parameters. The VSM can determine using a sequence of load flow solutions for each loading conditions. In order to reduce computational effort in deterring the VSM using a sequence of load flow solutions, various researchers have focused on network reduction based stability indices.

In literature, various techniques are proposed for determining the stability of power system at a specific loading conditions and consequently VSM, but paid low attention on distribution system [2, 3]. In specific, distribution systems experience with diversified loads varies from high to low in different timings. Also, these networks have low $X / R$ ratio and consequently suffer with high $I R$ and $I X$ voltage drops, which may trigger for voltage collapse scenario. Chakravorty et al. [4] have introduced a novel stability index (SI) for assessing the voltage stability of each node and consequently overall stability of the system, defined as the lowest SI value of the all nodes. The node which has lowest index value is treated as critical node and most sensitive for voltage collapse. The proposed index used the branch impedance parameters and voltage magnitude of the starting node and effective loads at ending node, determined using the load flow technique developed by Das et al. [5]. Eminoglu et al. [6, 7], introduced a new stability index using the branch parameters and its power flows. The same index is extended to determine stability of larger size systems based on topology. According to this index also, the weakest node for voltage collapse is the node which has lowest index values and considered the same for defining the overall stability index of the system. In Mahmoud et al. [8], a novel stability index (Cat_VSI) proposed for determining the proximity of voltage collapse using catastrophe theory and load flow technique [5]. The index starts from 0.25 at no-load to zero at critical loading conditions. In Ranjan et al. [9], a simplified voltage stability index is proposed based on load flow technique [5]. Ideally, this index starts from 0.5 at no-load to zero at critical loading conditions. In Soheil Derafshi Beigvand et al. [10], an extended version for the index proposed by Chakravorty and Das [4] and later its simplified version is presented. Notably, these two indices used the impedance angle of the branch and node load angles instead of power flows of the branch. By observing these 
indices, the sending node voltage plays a key role for maintain stability at receiving node. Considering Advanced Metering Infrastructure (AMI) like Phasor Measuring Unit (PMU) these two indices are more suitable for Smart Grid (SG) environment. Line Stability Index (LSI) is introduced using load angles, branch parameters and current and reactive power of receiving node [11]. Importantly, this index seems to be independent of voltage magnitudes but required indirectly while calculating the branch current. According to LSI, the weakest branch can be determined by identifying the maximum LSI of all branches. In Pitchaimuthu Raja et al. [12], Voltage Collapse Index (VCI) is introduced for identifying the proximity of voltage collapse point and correspondingly steady-state stability margin. The validity of VCI is compared with Continuous Power Flow (CPF) based PV curve. It has been observed that the VCP becomes zero at the nose point of PV curve and indicates the instability conditions. In Partha Kayal et al. [13], a two-bus equivalent based voltage stability index is proposed. As per this index, the minimum value indicates more voltage stable and ensures low loss in the system configuration. In Kumar et al. [14], maximum loadability index has been proposed using feasible solution of the receiving end node voltage equation. It has also been highlighted that the RDS loadability is dependent on its configuration and load growth. In Jasmon et al. [15], a singleline equivalent network based L-index has been proposed for determining the critical loading limit for the entire system before voltage collapses. According to this stability criterion, L-index should become 1 for voltage instability. In Moghavvemi et al. [16], introduced another stability index to determine the relative distance to the point of voltage collapse using single-line equivalent network. Also, it emphasized the low power factor impact on system loading condition and can be one of the major reasons for voltage collapse. Hamada et al. [17], proposed a simple and new stability index $\left(L_{v}\right)$ to determine the voltage stability and suitable to determine critical active power loading of the system and compared with the indices $L$ and $L_{p}$. In comparison to the indices $L$ and $L_{p}$, the index $L_{v}$ has very good agreement with the insolvability condition of system using conventional load flow techniques [18]. In Banerjee et al. [19], a local voltage stability index has been proposed to determine the weakest branch of the distribution system. According to this criterion, the branch which may reach to unity as loading increases can treat as weakest branch in the network. In Aman et al. [20], the index $L_{p}$ has been modified and termed as Power Stability Index $(P S I)$ for incorporating the distribution generation (DG) power and used to determine candidate location for integrating the DGs in the distribution system. In simple, there is no difference between indices $L_{p}$ and PSI.

In similar, different indices for assessing voltage stability of the distribution systems can be found in literature [3]. From the aforementioned literature, it is observed that the majority of works have been used mainly constant power (CP) load model in their methodology. A limited works have also analyzed using constant current (CI) and constant impedance (CZ) load models. But none of them have focused on the residential, industrial and commercial type of load models. In addition, the literature is also not focused the agriculture and electric vehicle (EV) loads. According to separate feeder concept for agriculture sector and increasing high EV load penetrations, assessment of voltage stability is essential. This paper made an attempt to focus on voltage stability analysis considering the above mentioned distinguished type of load models. In the literature, it is also proved that the network topology can also influence the system performance and voltage stability significantly [21].

In light of the above reviewed works, the static voltage stability analysis of radial distribution system is highly dependent on its configuration, type of load and loading conditions. In this paper, the impact of different types of loads is analyzed on IEEE 33-bus system considering its basic and optimal configurations. The rest of the paper is arranged as follows: Section 2 presents the mathematical modeling involved in static voltage stability analysis of RDA. Section 3 explains the voltage dependent modeling for different types of loads. Section 4 presents the simulation results of IEEE 33-bus system for basic and optimized configurations. In Section 5, the major research findings and observations are presented.

\section{VOLTAGE STABILITY ASSESSMENT}

The stability index proposed by Chakravorty and Das [4] is used for assessing the static voltage stability analysis of the system. A typical two-bus test system interconnected by a branch having impedance of $Z_{(p q)}$ is shown in Figure 1.

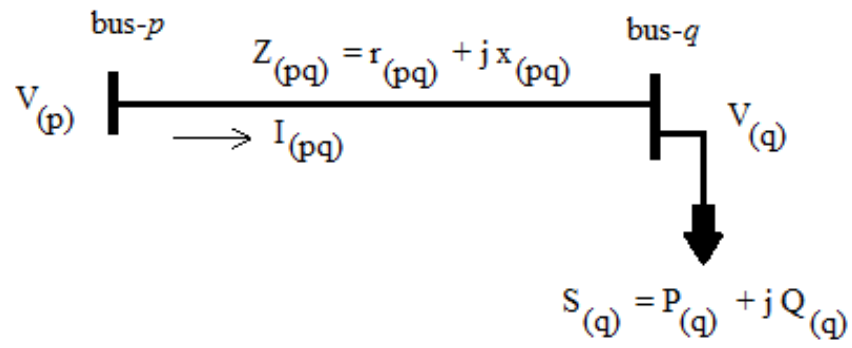

Figure 1. Typical two-bus RDS network

The complex power connected at bus- $q$ is $S_{(q)}=P_{(q)}+j Q_{(q)}$. The current flow through branch, $I_{(p q)}$ is equivalnet to the current drawn by the load at bus- $q, I_{(q)}$ and is given by,

$$
\begin{gathered}
I_{(p q)}=I_{(q)}=\left(S_{(q)} / V_{(q)}\right)^{*} \\
=\frac{P_{(q)}-j Q_{(q)}}{\left|V_{(q)}\right| \angle-\delta_{(q)}}=\frac{\left|V_{(p)}\right| \angle \delta_{(p)}-\left|V_{(q)}\right| \angle \delta_{(q)}}{r_{(p q)}+j x_{(p q)}}
\end{gathered}
$$

By simplification, Eq. (2) can be written as,

$$
\begin{gathered}
\left\{\left|V_{(p)}\right| \angle \delta_{(p)}-\left|V_{(q)}\right| \angle \delta_{(q)}\right\}\left(\left|V_{(q)}\right| \angle-\delta_{(q)}\right)= \\
\left(P_{(q)}-j Q_{(q)}\right)\left(r_{(p q)}+j x_{(p q)}\right) \\
\left\{\left|V_{(p)}\right|\left|V_{(q)}\right| \angle\left(\delta_{(p)}-\delta_{(q)}\right)\right\}-\left|V_{(q)}\right|^{2}= \\
\left(P_{(q)}-j Q_{(q)}\right)\left(r_{(p q)}+j x_{(p q)}\right)
\end{gathered}
$$

By separating real and imaginary parts, we have,

$$
\left|V_{(p)}\right|\left|V_{(q)}\right| \cos \left(\delta_{(p q)}\right)=P_{(q)} r_{(p q)}+Q_{(q)} x_{(p q)}+\left|V_{(q)}\right|^{2}
$$




$$
\left|V_{(p)}\right|\left|V_{(q)}\right| \sin \left(\delta_{(p q)}\right)=P_{(q)} x_{(p q)}-Q_{(q)} r_{(p q)}
$$

Squaring and adding Eq. (5) and Eq. (6) and then simplifying, we have

$$
\left|V_{(q)}\right|^{4}-k_{1}\left|V_{(q)}\right|^{2}+k_{2}=0
$$

where,

$$
\begin{gathered}
k_{1}=\left|V_{(p)}\right|^{2}-2 P_{(q)} r_{(p q)}-2 Q_{(q)} x_{(p q)} \\
k_{2}=\left(P_{(q)}^{2}+Q_{(q)}^{2}\right)\left(r_{(p q)}^{2}+x_{(p q)}^{2}\right)
\end{gathered}
$$

From the feasible solution for Eq. (7), the voltage magnitude of bus-q and its phase angles are given by:

$$
\begin{gathered}
\left|V_{(q)}\right|=\left[\frac{1}{2} k_{1}+\left(k_{1}^{2}-4 k_{2}\right)^{\frac{1}{2}}\right]^{\frac{1}{2}} \\
\delta_{(q)}=\delta_{(p)}-\tan ^{-1}\left[\frac{\left(P_{(q)} x_{(p q)}-Q_{(q)} r_{(p q)}\right)}{\left|V_{(q)}\right|^{2}+P_{(q)} r_{(p q)}+Q_{(q)} x_{(p q)}}\right]
\end{gathered}
$$

Using voltage profile, the real and reactive powers of a branch and consequently total system losses can determine using the following:

$$
\begin{gathered}
P_{l o s s(p q)}=r_{(p q)}\left(\frac{P_{(q)}^{2}+Q_{(q)}^{2}}{\left|V_{(q)}\right|^{2}}\right) \\
Q_{l o s s(p q)}=x_{(p q)}\left(\frac{P_{(q)}^{2}+Q_{(q)}^{2}}{\left|V_{(q)}\right|^{2}}\right) \\
P_{T, l o s s}=\sum_{p q=1}^{n b r} P_{l o s s(p q)} \\
Q_{T, l o s s}=\sum_{p q=1}^{n b r} Q_{l o s s(p q)}
\end{gathered}
$$

where, $\left|V_{(p)}\right|$ and $\left|V_{(q)}\right|$ are the voltage magnitudes at bus- $p$ and bus- $q$ respectively; $\delta_{(p)}$ and $\delta_{(q)}$ are the load angles of bus- $p$ and bus- $q$ respectively; $r_{(p q)}$ and $x_{(p q)}$ are the resistance and reactance of the branch impedance respectively; $P_{(q)}$ and $Q_{(q)}$ are the real and reactive power loads at bus- $q$ respectively. $P_{l o s s(p q)}$ and $Q_{l o s s(p q)}$ are the real and reactive power losses in branch $p-q$ respectively; $P_{T, \text { loss }}$ and $Q_{T, \text { loss }}$ are the real and reactive power losses of the total distribution system respectively; $n b r$ is number of branches in the network.

Initially, $P_{l o s s(p q)}$ and $Q_{l o s s(p q)}$ for all branches are set to zero. By knowing bus-p voltage magnitude and its load angle $\left(\left|V_{(p)}\right|=1.00 p . u\right.$. \& $\left.\delta_{(p)}=0\right)$, the initial effective powers $P_{(q)}$ and
$Q_{(q)}$ are determined by summing all the loads beyond bus- $q$ plus local load of bus- $q$. Later, the real and reactive power losses of branch pq are determined using Eq. (12) and Eq. (13). By proceeding for all the branches, the total power loss of the system can be determined using Eq. (14) and Eq. (15). This stage will complete one iteration. By updating the businjections $\quad P_{(q)}=P_{(q)+} P_{\text {loss }(p q)} \quad$ and $\quad Q_{(q)}=Q_{(q)}+Q_{\text {loss }(p q)}$, the procedure continues until satisfies the convergence criterion, error, $\varepsilon$ is defined as $\max \left(\left|V_{(n)}^{i t r+1}\right|-\left|V_{(n)}^{i t r}\right|\right) \leq 10^{-5}$ (i.e., the maximum of change in voltage magnitudes between two consecutive iterations of all buses).

The feasible solution for Eq. (9) can exist only by satisfying the following condition,

$$
k_{1}^{2}-4 k_{2} \geq 0
$$

After substituting $k_{1}$ and $k_{2}$ as defined in Eq. (8) \& Eq. (9), Eq. (16) can be written as,

$$
\begin{aligned}
& \left|V_{(q)}\right|^{4}-4\left(x_{(p q)} P_{e f f(q)}-r_{(p q)} Q_{e f f(q)}\right)^{2}- \\
& 4\left(r_{(p q)} P_{e f f(q)}+x_{(p q)} Q_{e f f(q)}\right)\left|V_{(p)}\right|_{2}^{2} \geq 0
\end{aligned}
$$

where, $P_{\text {eff }(q)}$ and $Q_{e f f(q)}$ are the effective real and reactive loadings at bus- $q$, which include connected load and losses.

Therefore, voltage stability index (VSI) for bus- $q$ is defined by,

$$
\begin{gathered}
V S I_{(q)}=\left|V_{(q)}\right|^{4}-4\left(x_{(p q)} P_{e f f(q)}-r_{(p q)} Q_{e f f(q)}\right)^{2} \\
4\left(r_{(p q)} P_{e f f(q)}+x_{(p q)} Q_{e f f(q)}\right)\left|V_{(p)}\right|_{2}^{2} \geq 0
\end{gathered}
$$

For the stable operation, $V S I_{(q)} \geq 0$, for $q=1,2, \ldots$, nbus. The lowest $V S I_{(q)}$ among all buses is said to be the overall system stability condition.

\section{VOLTAGE DEPENDENT LOAD MODELING}

In conventional load studies, the loads are presumed constant irrespective of their associated bus voltage magnitude. In contrast, the voltage profile of the distribution system is always varying due to distinct change changes in the load profile from low to high. Also, the distribution system voltage profile subjected to change w.r.t. type of load. In general, the distribution systems serve different type of loads and their characteristics and profile are not same. Due to these, the power consumption by different types of loads may not be constant as mentioned on their name plate, but continuously vary w.r.t. the changes in voltage magnitude and frequency of the associated bus. In order to accommodate this fact, the power ratings of different loads have been modeled using voltage-dependent load modeling. According to this, the real and reactive power demands of a load are given by:

$$
\begin{gathered}
P_{d, i}=P_{d, i}^{(0)} \times\left(\left|V_{i}\right| /\left|V_{i}^{(0)}\right|\right)^{\alpha} \\
Q_{d, i}=Q_{d, i}^{(0)} \times\left(\left|V_{i}\right| /\left|V_{i}^{(0)}\right|\right)^{\beta}
\end{gathered}
$$


where, $P_{d, i}^{(0)}$ and $Q_{d, i}^{(0)}$ are the active and reactive power loads at bus-i at nominal voltage respectively; $P_{d, i}$ and $Q_{d, i}$ are active and reactive power loads at actual voltage respectively; $\left|V_{i}\right|$ and $\left|V_{i}^{(0)}\right|$ are the actual voltage magnitude and nominal voltage magnitudes respectively; $\alpha$ and $\beta$ are the exponents of active and reactive power loads respectively. The exponents for Constant power (CP), Constant current (CI), Constant impedance (CZ), Agricultural load (AL) (i.e., pumps, fans other motors) can be found [22]. The exponents for Electric vehicle (EV) load are given by Satyanarayana et al. [22], Kongjeen and Bhumkittipich [23]. The exponents for residential (RL), industrial (IL) and commercial (CL) loads are given by Abdi and Afshar [24].

\section{RESULTS AND DISCUSSION}

The proposed methodology for evaluating the static voltage stability of RDSs is applied on the standard 33-bus balanced test system. The voltage stability is computed for the basic topology and optimal reconfigured topologies for different load models. The optimal reconfigured topology is taken from the existing literature [25]. The single line diagram of test system for basic topology is given in Figure 2. The test system has 32-branches (black color lines) and 5-tie-lines (dotted lines) [26]. For the analysis purpose, constant power, constant current, constant impedance, residential, industrial, commercial, agricultural, electric vehicle loads are considered in this work. The exponentials of active and reactive powers for different loads are given in Table 1.

Generally, the optimal network reconfiguration subjected to operational constraints, radiality constraints and aimed to optimize an objective function like loss minimization, voltage stability enhancement, loadability enhancement. In this paper, the optimal configuration of IEEE 33-bus is directly taken as obtained in many literature paper [25].

The optimal reconfiguration of the test system is arrived by closing the tie-lines 33 (8-21), 34 (9-15), 35 (12-22) \& 36 (1833 ) and by opening the branches 7 (7-8), 9 (9-10), 14 (14-15) \& 32 (32-33) and tie-line 37 (25-29 respectively. The optimal reconfiguration with branch sequence for BW/FW load flow study is given in Figure 3.

The performance is measured in terms of active and reactive power losses, voltage profile, and voltage stability index. The results for different types of loads for basic topology and optimized topology are given in Table 2 and Table 3 respectively. In Table 2 and Table 3, column 1 represents the type of load, column 2 and 3 represent the total real and reactive power loads of the network respectively, column 4 and 5 represent the total real and reactive power distribution losses respectively; column 6 represnts the voltage stability of the system and column 7 indicates the lowest voltage magnitude in the entire system with associated bus details.

Table 1. Exponentials of active and reactive powers for different loads

\begin{tabular}{cccccc}
\hline Load & $\boldsymbol{\alpha}$ & $\boldsymbol{\beta}$ & Load & A & $\boldsymbol{\beta}$ \\
\hline $\mathrm{CP}$ & 0 & 0 & $\mathrm{IL}$ & 0.18 & 6 \\
$\mathrm{CI}$ & 1 & 1 & $\mathrm{CL}$ & 1.51 & 3.4 \\
$\mathrm{CZ}$ & 2 & 2 & $\mathrm{AL}$ & 0.08 & 1.60 \\
$\mathrm{RL}$ & 0.92 & 4.04 & $\mathrm{EV}$ & 2.59 & 4.06 \\
\hline
\end{tabular}

At nominal voltage profile, the test system has real power load of $3715 \mathrm{~kW}$ and reactive load of $2300 \mathrm{kVAr}$ respectively. For the basic topology, the load flow resulted for total real and reactive power losses around $202.67 \mathrm{~kW}$ and $135.14 \mathrm{kVAr}$ respectively. The average voltage deviation index (AVDI) and voltage stability index (VSI) are 0.0035 and 0.694 respectively. The AVDI is calculated w.r.t. reference/sub-station bus voltage i.e., 1.0 p.u. Also, the system is observed with lowest voltage magnitude of 0.9131 p.u. at bus-18. The load flow is performed for different types of loads as mentioned in section 2. The effective new loading with voltage-dependent load modeling and correspondingly system performance are given in Table 2.

The load flow study is repeated for all types of loads considering optimal topology as given in Figure 3. At nominal voltage profile, the test system loading conditions are remaining same but the performance is improved significantly. The active power losses are decreased to $139.53 \mathrm{~kW}$ from $202.67 \mathrm{~kW}$, reactive power losses are decreased to 102.29 $\mathrm{kVAr}$ from $135.14 \mathrm{kVAr}$, the AVDI is decreased to 0.0015 from 0.0035 , VSI is improved to 0.7722 from 0.694 and the lowest voltage magnitude at bus-18 is raised to 0.9378 p.u. from 0.9131 p.u. Hence, it can be said that the optimal topology has resulted for improved performance in all the aspects. The analysis is carried for different types of loads considering optimal topology and is given in Table 3.

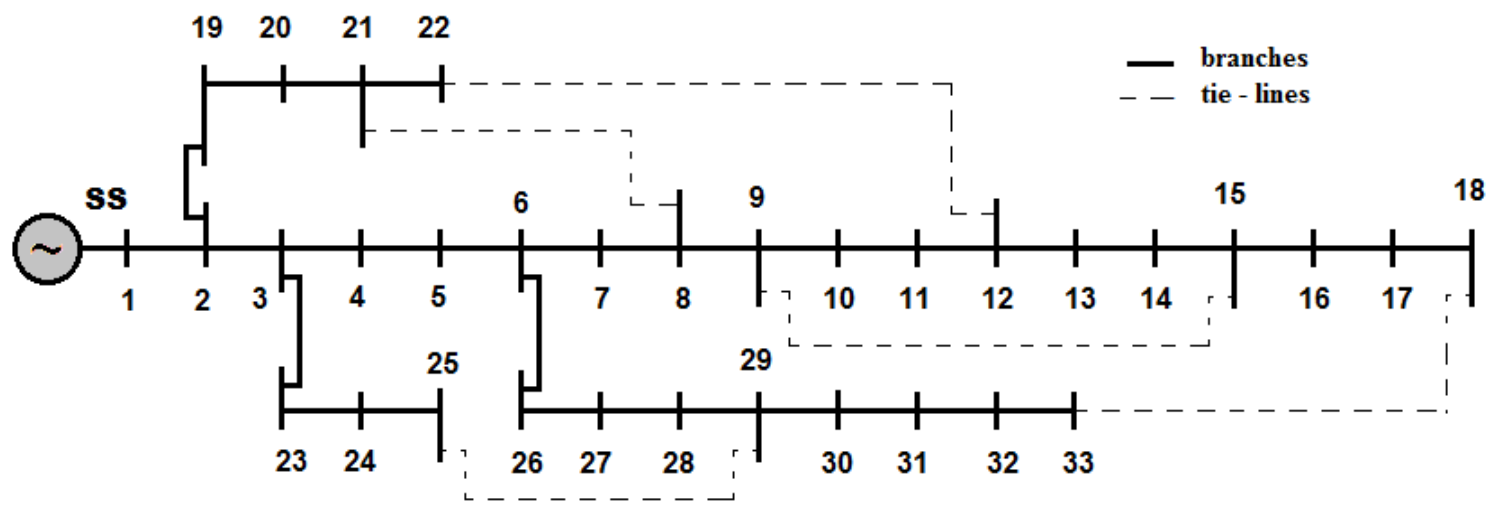

Figure 2. The basic topology of IEEE 33-bus test system [26] 


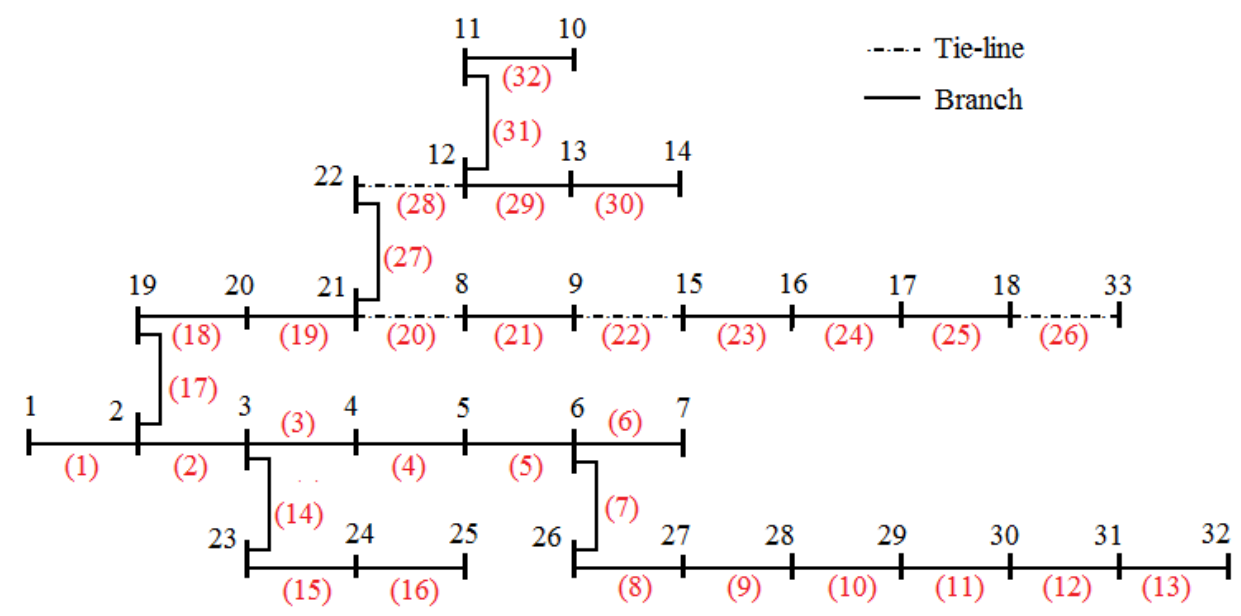

Figure 3. The optimal reconfigured IEEE 33-bus test system [25]

Table 2. The performance analysis and voltage stability analysis under standard topology

\begin{tabular}{|c|c|c|c|c|c|c|c|}
\hline Load & $P_{\text {load }}(\mathrm{kW})$ & Qload $_{\text {lkVAr) }}$ & $P_{\text {loss }}(\mathrm{kW})$ & Qloss $_{\text {(kVAr) }}$ & AVDI & VSI & $V_{\min }$ (p.u.) \\
\hline $\mathrm{CP}$ & 3715.00 & 2300.00 & 202.67 & 135.14 & 0.0035 & 0.6940 & 0.9131 \\
\hline CI & 3543.25 & 2181.01 & 176.62 & 117.54 & 0.0031 & 0.7132 & 0.9194 \\
\hline $\mathrm{CZ}$ & 3382.25 & 2069.91 & 165.96 & 109.69 & 0.0027 & 0.7300 & 0.9248 \\
\hline $\mathrm{AL}$ & 3700.44 & 2108.14 & 186.82 & 124.37 & 0.0033 & 0.7044 & 0.9165 \\
\hline $\mathrm{EV}$ & 3291.71 & 1862.49 & 159.49 & 95.73 & 0.0023 & 0.7460 & 0.9299 \\
\hline $\mathrm{CL}$ & 3459.99 & 1925.93 & 170.45 & 99.87 & 0.0027 & 0.7308 & 0.9250 \\
\hline RL & 3556.79 & 1864.37 & 176.47 & 95.65 & 0.0027 & 0.7264 & 0.9236 \\
\hline IL & 3683.33 & 1690.95 & 184.08 & 83.95 & 0.0027 & 0.7249 & 0.9231 \\
\hline
\end{tabular}

Table 3. The performance analysis and voltage stability analysis under optimized topology

\begin{tabular}{cccccccc}
\hline Load & Pload $_{(\mathbf{k W})}$ & Qload $_{(\mathbf{k V A r})}$ & Ploss $\left._{\mathbf{k W}}\right)$ & Qloss $_{\text {(kVAr) }}$ & AVDI & VSI & $\mathbf{V}_{\min }(\mathbf{p . u .})$ \\
\hline CP & 3715.00 & 2300.00 & 139.53 & 102.29 & 0.0015 & 0.7722 & 0.9378 \\
CI & 3589.73 & 2212.42 & 127.48 & 93.41 & 0.0013 & 0.7828 & 0.9411 \\
CZ & 3470.13 & 2129.16 & 122.08 & 89.24 & 0.0012 & 0.7923 & 0.9439 \\
AL & 3704.61 & 2159.56 & 131.67 & 96.67 & 0.0014 & 0.7797 & 0.9401 \\
EV & 3401.65 & 1968.77 & 118.81 & 81.69 & 0.0011 & 0.8031 & 0.9472 \\
CL & 3528.28 & 2018.53 & 124.23 & 84.16 & 0.0012 & 0.7948 & 0.9447 \\
RL & 3599.86 & 1970.26 & 127.11 & 82.01 & 0.0012 & 0.7937 & 0.9443 \\
IL & 3692.13 & 1830.80 & 130.66 & 75.69 & 0.0012 & 0.7958 & 0.9450 \\
\hline
\end{tabular}

In comparison to the CP load model, the percentage of active power load decrement with different types of load models is given Figure 4. It is observed for the basic topology, the decrement in active power demand on the system for CI load $(0.919 \%)$, CZ load $(0.925 \%)$, agriculture load $(0.917 \%)$, EV load $(0.93 \%)$, commercial load $(0.925 \%)$, residential load $(0.924 \%)$ and industrial load $(0.923 \%)$, respectively. Similarly, for optimized topology, it has observed for CI load (0.941\%), CZ load (0.944\%), agriculture load $(0.94 \%)$, EV load $(0.947 \%)$, commercial load $(0.945 \%)$, residential load $(0.944 \%)$ and industrial load $(0.945 \%)$, respectively. From this comparison, it can be said that the active power demand is decreased considerably with the optimized topology than basic topology for all types of load models.

In comparison to the $\mathrm{CP}$ load model, the percentage of reactive power load decrement with different types of load models is given Figure 5. It is observed for the basic topology, the decrement in reactive power demand on the system for CI load (13.02\%), CZ load (18.83\%), agriculture load (7.97\%), EV load (29.16\%), commercial load (26.1\%), residential load (29.22\%) and industrial load (37.88\%), respectively. Similarly, for optimized topology, it has observed for CI load (30.88\%), CZ load (33.96\%), agriculture load (28.47\%), EV load (39.55\%), commercial load $(37.72 \%)$, residential load (39.31\%) and industrial load (43.99\%), respectively. From this comparison, it can be said that the reactive power demand is decreased significantly with the optimized topology than basic topology for all types of load models. Notably, the reactive power demand on the system is highly influenced with the optimized topology than basic topology.

In comparison to the CP load model, the percentage of active power loss decrement with different types of load models is given Figure 6. It is observed for the basic topology, the decrement in active power loss in the system for CI load 
(0.919\%), CZ load (0.925\%), agriculture load (0.917\%), EV load $(0.93 \%)$, commercial load $(0.925 \%)$, residential load $(0.924 \%)$ and industrial load $(0.923 \%)$, respectively. Similarly, for optimized topology, it has observed for CI load $(0.941 \%)$, CZ load (0.944\%), agriculture load $(0.94 \%)$, EV load
$(0.947 \%)$, commercial load $(0.945 \%)$, residential load $(0.944 \%)$ and industrial load $(0.945 \%)$, respectively. From this comparison, it can be said that the active power loss is decreased considerably with the optimized topology than basic topology for all types of load models.

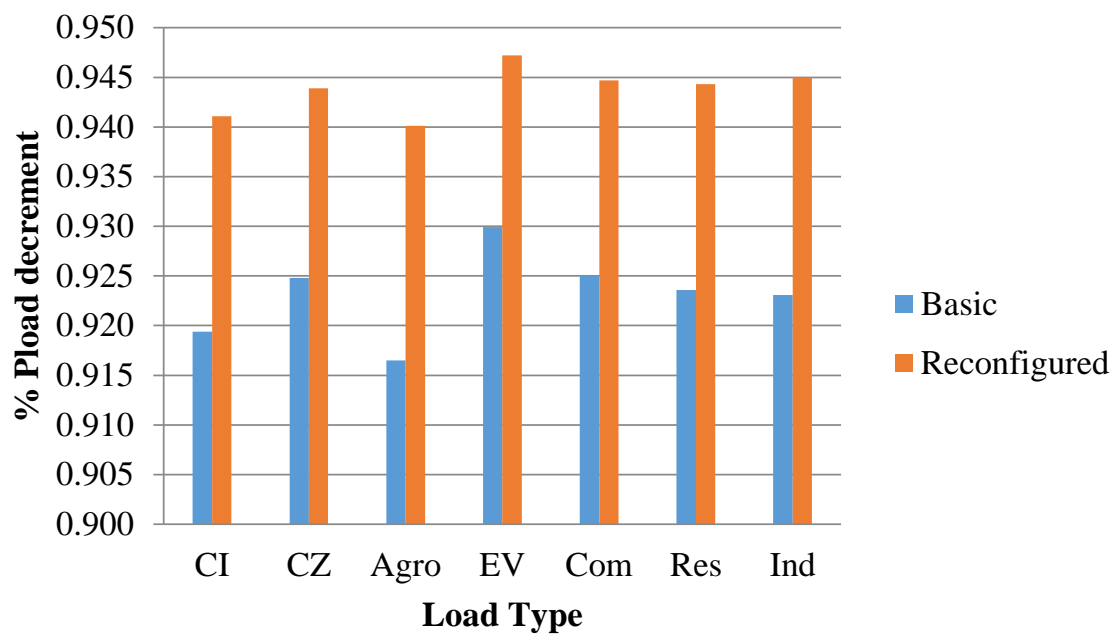

Figure 4. \% Change in $\mathrm{P}_{\text {load }}$ for different types of loads under basic and optimized topology

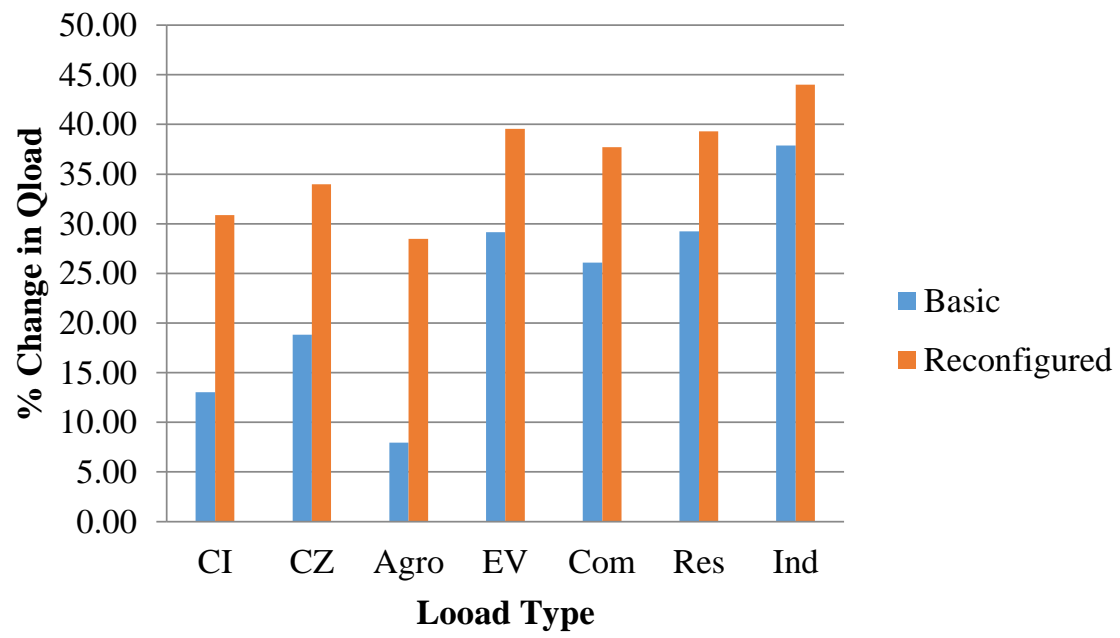

Figure 5. \% Change in $\mathrm{Q}_{\text {load }}$ for different types of loads under basic and optimized topology

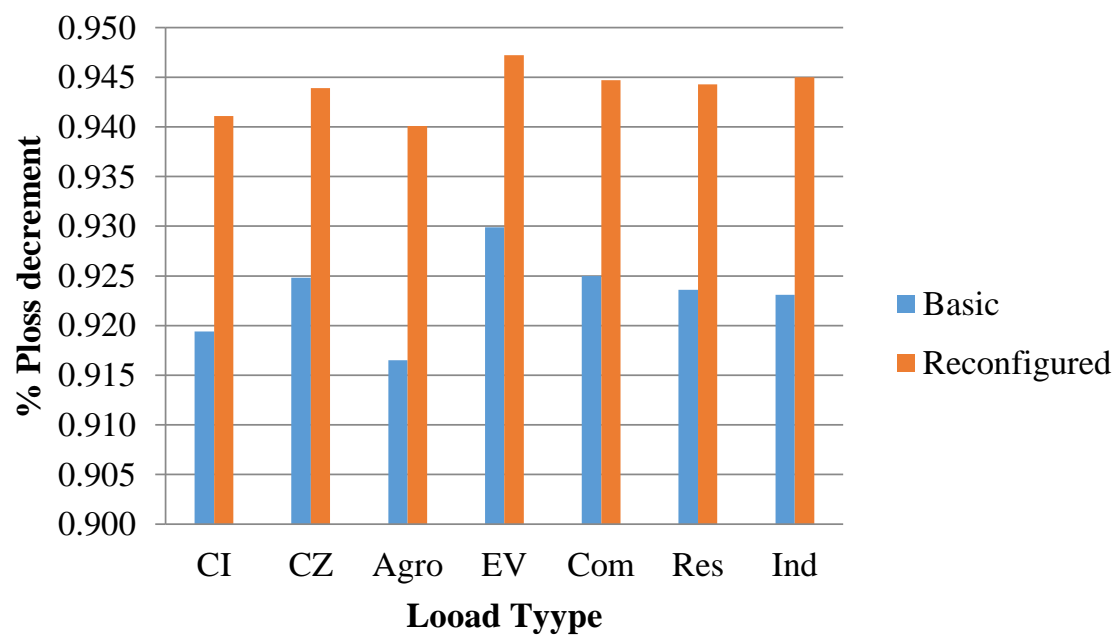

Figure 6. $\% \mathrm{P}_{\text {loss }}$ decrement for different types of loads under basic and optimized topology 


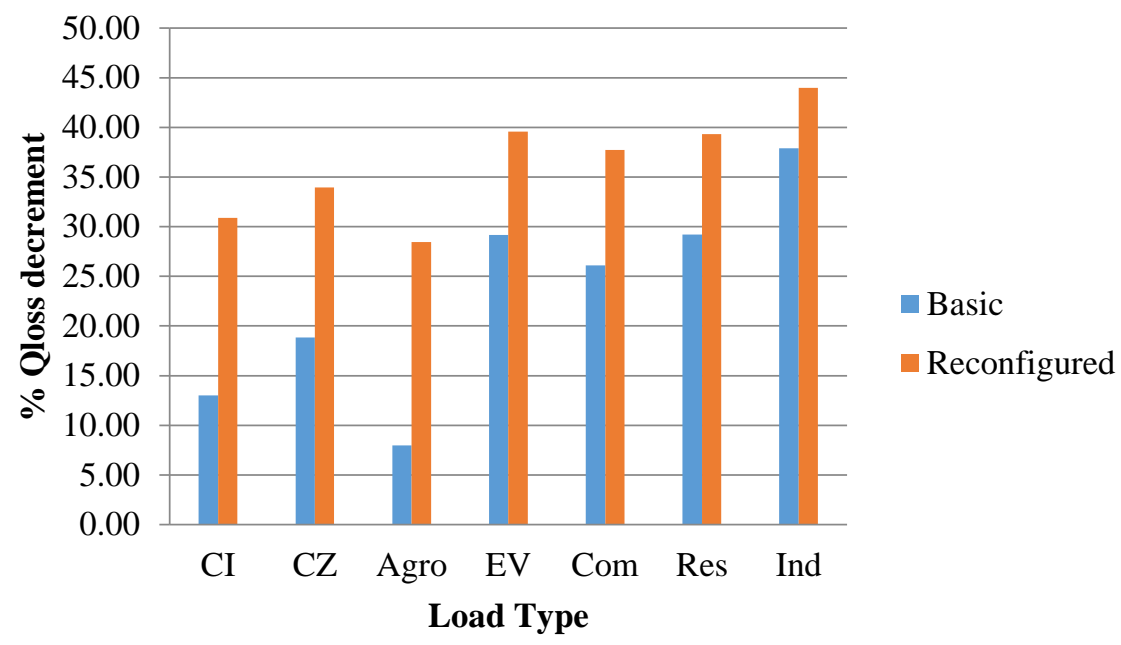

Figure 7. \% $\mathrm{Q}_{\text {loss }}$ decrement for different types of loads under basic and optimized topology

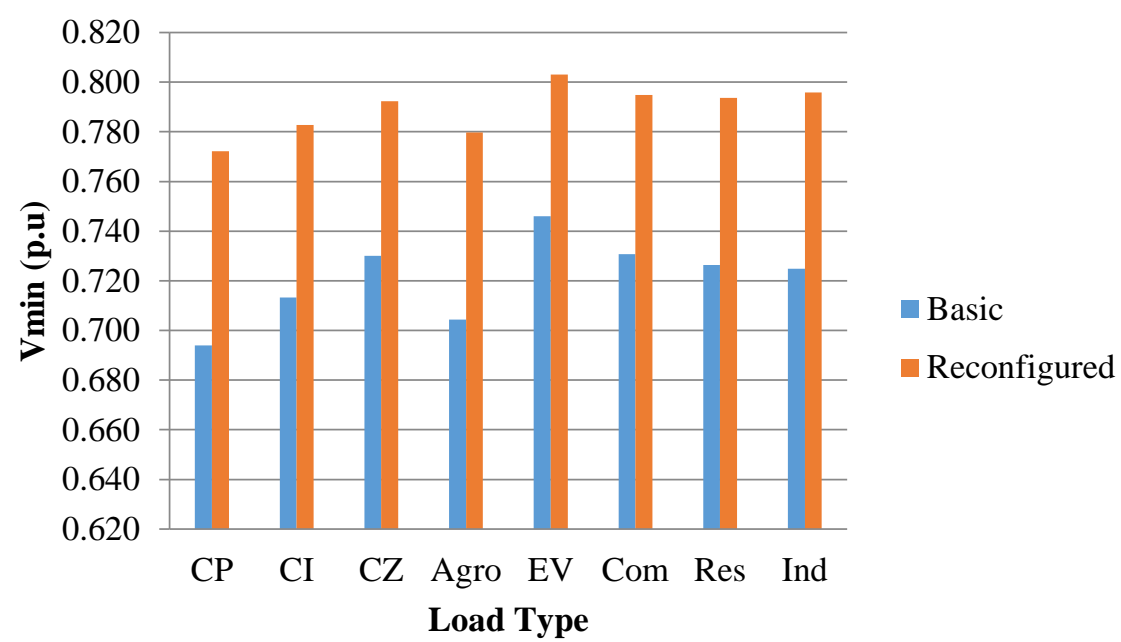

Figure 8. $V_{\min }$ for different types of loads under basic (at bus-18) and optimized topology (at bus-32)

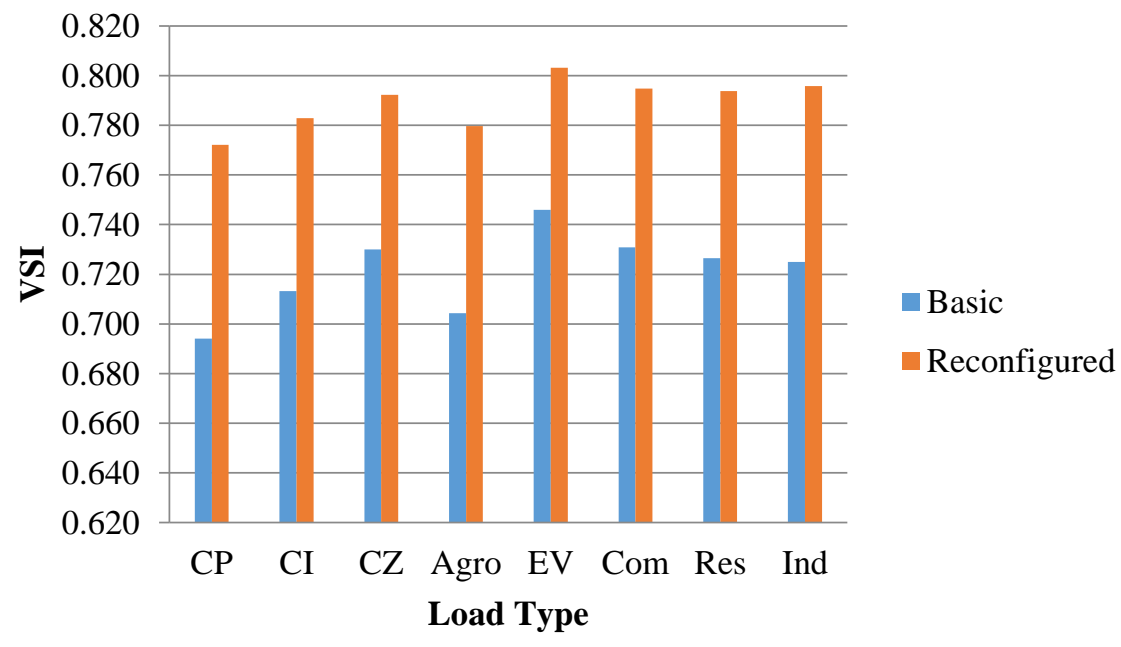

Figure 9. VSI under different types of loads for basic and optimized topology

In comparison to the CP load model, the percentage of reactive power loss decrement with different types of load models is given Figure 7. It is observed for the basic topology, the decrement in reactive power loss in the system for CI load (13.02\%), CZ load (18.83\%), agriculture load (7.97\%), EV load (29.16\%), commercial load (26.1\%), residential load $(29.22 \%)$ and industrial load $(37.88 \%)$, respectively. Similarly, for optimized topology, it has observed for CI load (30.88\%), CZ load (33.96\%), agriculture load (28.47\%), EV load $(39.55 \%)$, commercial load $(37.72 \%)$, residential load (39.31\%) and industrial load (43.99\%), respectively. From this comparison, it can be said that the reactive power loss is decreased significantly with the optimized topology than basic topology for all types of load models. Also, this phenomenon 
is proportional to the reactive power demand decrement than active power demand as seen in earlier.

The comparison of minimum voltage profile in the test system for different types of load models is given for both the topologies in Figure 8. It is observed for the basic topology, the minimum voltage is observed at bus-18, whereas, it is observed at bus-32 in the optimized topology. As given, $\mathrm{CP}$ load (0.913), CI load (0.919), CZ load (0.925), agriculture load (0.917), EV load (0.93), commercial load (0.925), residential load (0.924) and industrial load (0.923), respectively. Similarly, for optimized topology, it has observed for CP load (0.938), CI load (0.941), CZ load (0.944), agriculture load (0.94), EV load (0.947), commercial load (0.945), residential load (0.944) and industrial load (0.945), respectively. From this comparison, it can be said that the voltage profile of the test system is significantly improved with the optimized topology for all types of load models. Also, the voltage profile is better than CP load model for the both topologies.

The comparison of voltage stability index for different load models is given for both the topologies in Figure 9. It is observed for the basic topology, the VSI of the system for CP load (0.694), CI load (0.713), CZ load (0.73), agriculture load (0.704), EV load (0.746), commercial load (0.731), residential load (0.726) and industrial load (0.725), respectively. Similarly, for optimized topology, it has observed for CP load (0.772), CI load (0.783), CZ load (0.792), agriculture load (0.78), EV load (0.803), commercial load (0.795), residential load (0.794) and industrial load (0.796), respectively. From this comparison, it can be said that the voltage stability of the test system is significantly improved with the optimized topology for all types of load models.

\section{CONCLUSION}

In this paper, the voltage stability analysis of radial distribution system is evaluated under basic and optimal reconfigured topologies. The impact of voltage-dependent load modeling of different types of loads is analyzed in details. The simulation studies are performed on standard IEEE 33bus test system considering constant power (CP), constant current $(\mathrm{CI})$, constant impedance $(\mathrm{CZ})$, residential, industrial, commercial, agricultural, and electric vehicle (EV) loads. At first, the performance is measured interms of change in loading level, losses and voltage profile w.r.t. type of load and correspondingly voltage stability is evaluated. Later, the analysis is repeated by considering optima configuration. The results obtained are shown that the performance and voltage stability of the distribution system can be improved significantly by altering the topology optimaly. In comprehension, the voltage profile is better than $\mathrm{CP}$ model for all other types of load models and hence, the active power demand and losses are reduced considerably. Similarly, the reactive power demand and reactive power losses are highly influenced with the improved voltage profile and consequently the system has better voltage stability than CP load model for all the types of load models. The same phenomenon is observed effectively with the optimized topology than basic topology. In addition to the network topology, the impact of distribution generation (DG) on voltage stability needs to be analyzed for different types of loads and their combinations (composite load) and considered as the future scope of this work.

\section{REFERENCES}

[1] Alhelou, H.H., Hamedani-Golshan, M.E., Njenda, T.C., Siano, P. (2019) A survey on power system blackout and cascading events: research motivations and challenges, Energies, 12(4): https://doi.org/10.3390/en12040682

682.

[2] Nagendra, P., Datta, T., Halder, S., Paul, S. (2010). Power system voltage stability assessment using network equivalents - a review. Journal of Applied Sciences, 10(18): 2147-2153.

[3] Modarresi, J., Gholipourn, E., Khodabakhshian, A. (2016). A comprehensive review of the voltage stability indices. Renewable and Sustainable Energy Reviews, 63: 1-12. https://doi.org/10.1016/j.rser.2016.05.010

[4] Chakravorty, M., Das, D. (2001). Voltage stability analysis of radial distribution networks. International Journal of Electrical Power \& Energy Systems, 23(2): 129-135. https://doi.org/10.1016/S0142-0615(00)000405

[5] Das, D., Kothari, D.P., Kalam, A. (1995). A simple and efficient method for load flow solution of radial distribution networks. International Journal of Electrical Power and Energy Systems, 17(5): 335-346. https://doi.org/10.1016/0142-0615(95)00050-0

[6] Eminoglu, U., Hocaoglu, M.H. (2007). A voltage stability index for radial distribution networks. 42nd International Universities Power Engineering Conference, Brighton, UK. https://doi.org/10.1109/UPEC.2007.4468982

[7] Eminoglu, U., Hocaoglu, M.H. (2009). A network topology-based voltage stability index for radial distribution networks. International Journal of Power and Energy $\quad$ Systems, 29(2): 131-143. https://doi.org/10.2316/Journal.203.2009.2.203-4280

[8] Mahmoud, G.A. (2012). Voltage stability analysis of radial distribution networks using catastrophe theory. IET Gener. Transm. Distrib., 6(7): 612-618. https://doi.org/10.1049/iet-gtd.2011.0530

[9] Ranjan, R., Das, D. (2003). Voltage stability analysis of radial distribution networks. Electric Power Components and Systems, 31(5): 501-511. https://doi.org/10.1080/15325000390127011

[10] Beigvand, S.D., Abdi, H., Singh, S.N. (2017). Voltage stability analysis in radial smart distribution grids. IET Gener. Transm. Distrib., 11(15): 3722-3730. https://doi.org/10.1049/iet-gtd.2016.1753

[11] Chakraborty, K., Deb, G., Deb, S. (2016). Voltage stability assessment in radial distribution system by line stability indicator (LSI) and its improvement using SVC. 2016 IEEE 1st International Conference on Power Electronics, Intelligent Control and Energy Systems (ICPEICES), Delhi, India. https://doi.org/10.1109/ICPEICES.2016.7853132

[12] Pitchaimuthu, R., Selvan, M.P., Kumaresan, N. (2013). Enhancement of voltage stability margin in radial distribution system with squirrel cage induction generator based distributed generators. IET Generation, Transmission \& Distribution, 7(8): 898-906. https://doi.org/10.1049/iet-gtd.2012.0579

[13] Kayal, P., Chanda, C.K., Dutta, T. (2012). Efficient distribution system realization using equivalent voltage stability indicator. IACSIT International Journal of Engineering and Technology, 4(3): 270-274. 
[14] Kumar, P., Singh, S. (2014). Comprehensive stability analysis of radial distribution system with load growth. 2014 IEEE 6th India International Conference on Power Electronics (IICPE), Kurukshetra, India pp. 1-6. https://doi.org/10.1109/IICPE.2014.7115733

[15] Jasmon, G.B., Lee, L.H.C.C. (1991). Distribution network reduction for voltage stability analysis and load flow calculations. International Journal of Electrical Power \& Energy Systems, 13(1): 9-13. https://doi.org/10.1016/0142-0615(91)90011-J

[16] Moghavvemi, M., Faruque, M.O. (2001). Technique for assessment of voltage stability in ill-conditioned radial distribution network. IEEE Power Engineering Review, 21(1): 58-60. https://doi.org/10.1109/39.893345

[17] Hamada, M.M., Wahab, M.A.A., Hemdan, N.G.A. (2010). Simple and efficient method for steady-state voltage stability assessment of radial distribution systems. Electric Power Systems Research, 80(2): 152-160. https://doi.org/10.1016/j.epsr.2009.08.017

[18] Wang, Y., da Silva, L.C.P., Xu, W., Zhang, Y. (2001). Analysis of ill-conditioned power-flow problems using voltage stability methodology. In IEE Proceedings Generation, Transmission and Distribution, 148(5): 384390. https://doi.org/10.1049/ip-gtd:20010424

[19] Banerjee, S., Chanda, C.K., Konar, S.C. (2009). Determination of the weakest branch in a radial distribution network using local voltage stability indicator at the proximity of the voltage collapse point. 2009 International Conference on Power Systems, Kharagpur, India, pp. 1-4. https://doi.org/10.1109/ICPWS.2009.5442777

[20] Aman, M.M., Jasmon, G.B., Mokhlis, H., Bakar, A.H.A. (2012). Optimal placement and sizing of a DG based on a new power stability index and line losses. International
Journal of Electrical Power \& Energy Systems, 43(1): 1296-1304. https://doi.org/10.1016/j.ijepes.2012.05.053

[21] Sultana, B., Mustafa, M.W., Sultana, U., Bhatti, A.R. (2016). Review on reliability improvement and power loss reduction in distribution system via network reconfiguration. Renewable and Sustainable Energy Reviews, 66: 297-310. https://doi.org/10.1016/j.rser.2016.08.011

[22] Satyanarayana, S., Ramana, T., Sivanagaraju, S., Rao, G.K. (2007). An efficient load flow solution for radial distribution network including voltage dependent load models. Electric Power Components and Systems, 35(5): 539-551. https://doi.org/10.1080/15325000601078179

[23] Kongjeen, Y., Bhumkittipich, K. (2018). Impact of plugin electric vehicles integrated into power distribution system based on voltage-dependent power flow analysis. Energies, 11(6): 1-16. https://doi.org/10.3390/en11061571

[24] Abdi, S., Afshar, K. (2013). Application of IPSO-Monte Carlo for optimal distributed generation allocation and sizing. International Journal of Electrical Power \& Energy Systems, 44(1): 786-797. https://doi.org/10.1016/j.ijepes.2012.08.006

[25] Mishra, S., Das, D., Paul, S. (2017). A comprehensive review on power distribution network reconfiguration. Energy System, 8: 227-284. https://doi.org/10.1007/s12667-016-0195-7

[26] Chandramohan, S., Atturulu, N., Kumudini Devi, R.P., Venkatesh, B. (2010). Operating cost minimization of a radial distribution system in a deregulated electricity market through reconfiguration using NSGA method. International Journal of Electrical Power \& Energy Systems, 32(2): 126-132. 